\title{
A randomised controlled trial. Shifting boundaries of doctors and physiotherapists in orthopaedic outpatient departments
}

Gavin Daker-White, Alison J Carr, Ian Harvey, Gillian Woolhead, Gordon Bannister, Ian Nelson, Max Kammerling

Abstract

Objective-To evaluate the effectiveness and cost effectiveness of specially trained physiotherapists in the assessment and management of defined referrals to hospital orthopaedic departments.

Design-Randomised controlled trial. Setting-Orthopaedic outpatient departments in two hospitals.

Subjects-481 patients with musculoskeletal problems referred for specialist orthopaedic opinion.

Interventions-Initial assessment and management undertaken by postmallo Fellowship junior orthopaedic surgeons, or by specially trained physiotherapists working in an extended role (orthopaedic physiotherapy specialists)

Main outcome measures-Patient centred measures of pain, functional disability and perceived handicap.

University of Bristol, Department of Social Medicine, Canynge Hall, Whiteladies
Road, Bristol BS8 2PR
G Daker-White G Daker-White

Rheumatology Outcomes Research Unit, Kings College Hospital (Dulwich), London A J Carr

University of East Anglia, School of Health, Policy and Practice, Norwich I Harvey

Department of Orthopaedic Surgery, Southmead Hospital, Bristol

Gennister

Department of Orthopaedic Surgery, Frenchay Hospital, Bristol

Somerset Health Authority, Taunton M Kammerling

Correspondence to:
Dr G Daker-White.

Accepted for publicatio 16 March 1999
Results-A total of 654 patients were eligible to join the trial, $481(73.6 \%)$ gave their consent to be randomised. The two arms

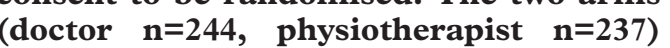
were similar at baseline. Baseline and follow up questionnaires were completed by 383 patients $(79.6 \%)$. The mean time to follow up was 5.6 months after randomisation, with similar distributions of intervals to follow up in both arms. The only outcome for which there was a statistically or clinically important difference between arms was in a measure of patient satisfaction, which favoured the physiotherapist arm. A cost minimisation analysis showed no significant differences in direct costs to the patient or NHS primary care costs. the patient or NHS primary care costs. Direct hospital costs were lower $(\mathbf{p}<0.00001)$ in the physiotherapist arm they were less likely to order radiographs and to refer patients for orthopaedic surgery than were the junior doctors (mean cost per patient in arm $=£ 498$, $\mathbf{n = 2 3 8 ) \text { . }}$

Conclusions-On the basis of the patient centred outcomes measured in this randomised trial, orthopaedic physiotherapy specialists are as effective as postFellowship junior staff and clinical assistant orthopaedic surgeons in the initial assessment and management of new referrals to outpatient orthopaedic departments, and generate lower initial direct hospital costs.

(F Epidemiol Community Health 1999;53:643-650) (mean cost per patient $=£ 256, \mathrm{n}=232$ ), as
The boundaries between different groups of health professionals are constantly shifting ${ }^{1}$ and there has been a discernible move in recent years towards the twin notions of skill mixing and the team approach in health care delivery. To date, the bulk of research and debate has centred on shifting role boundaries between doctors and nurses. ${ }^{1-8}$ The focus of this paper is on the shifting boundaries between doctors and physiotherapists in orthopaedic outpatient clinics. It involves a randomised comparison of the assessment and management of new referrals by surgeons in training with specially trained physiotherapists working in an extended role.

The specialist training of orthopaedic physitherapy specialists is typically provided on one to one basis by consultant orthopaedic urgeons and the tasks undertaken vary depending on the experience of the physiotherapist, the specialisms of the consultant and unit in question, and the nature of referrals. However, for the purposes of the assessment and initial management of new referrals, the im is to train the physiotherapist to function as a surgeon would - that is, to take a case history, perform a clinical examination, order appropriate investigations, make a provisional diagnosis, and arrange appropriate management and treatment interventions. Although musculoskeletal assessment forms a substantial part of physiotherapists' undergraduate and postgraduate training, these "extended role" physiotherapists perform exactly the same tasks as a surgeon would in the same circumstances. Their additional training includes radiographic analysis and radiological protecion.

Although earlier uncontrolled studies have attempted to describe the effectiveness of these pecially trained physiotherapists, ${ }^{9-11}$ to our knowledge, this is the first reported randomised evaluation. The first recorded use of a specially trained physiotherapist as a "first line filter system" for orthopaedic patients not obviously requiring surgical intervention, was in Exeter Health Authority in $1986{ }^{12}$ Since then, the numbers working in this extended role have increased rapidly, such that an inaugural meeting in 1997 of clinical physiotherapy specialists working in the UK, attracted 48 delegates. The initial growth in these posts has been linked to efforts to halt the rise in hospital outpatient waiting lists, reduce costs in hospital outpatient waiting lists, reduce cost and lower junior doctors hours of work. ${ }^{13}$ 
Given the lack of existing evaluative evidence concerning the extended role of physiotherapists in orthopaedics, the aim of this study was to compare the effectiveness and cost effectiveness of orthopaedic physiotherapy specialists and sub-consultant surgical staff (including clinical assistants), in the initial assessment and management of new general practitioner referrals to orthopaedic outpatients. The primary outcome measures used were patient centred measures of pain, function up: a mean of four months after randomisation. Secondary outcomes were patient centred measures of health comes were patient centred measures of health
status, psychological status, health related quality of life, self efficacy and satisfaction with care. Satisfaction of the general practitioner making the referral was also measured. The null hypothesis was that there would be no difference in outcomes or costs between patients seen by a doctor and those seen by a specially trained physiotherapist.

\section{Methods}

STUDY DESIGN

The study sample consisted of new general practitioner referrals to the Departments of Orthopaedic Surgery at Frenchay and Southmead hospitals, Bristol, between July 1996 and September 1997, from all but three referring practices in the Bristol area who refused to allow their patients to be included. All referral letters were screened by a consultant for suitability for inclusion in the trial. Patients deemed to require urgent treatment and those under the age of 18 years were excluded from the study. At Southmead, patients thought likely to require surgery were excluded. At Frenchay, suitable patients included patients for whom surgery was indicated. These differences between centres reflect the pragmatic nature of the trial. ${ }^{14}$ The study was approved by the ethics committees of both hospitals.

Eligible patients were sent a letter that briefly outlined the study and informed them that we had permission from their consultant and general practitioner to contact them. This letter was followed up by a telephone call from the trial office, when informed verbal consent was sought. Those who agreed to take part were immediately randomised to see either a physiotherapist or a sub-consultant surgeon by opening a sealed envelope, although each patient was not told at this point which staff they would see in clinic. The allocation schedule was devised using random number tables, before starting recruitment. It should be emphasised that the physiotherapists and orthopaedic surgeons in this trial were undertaking the compared were not different treatments or compared were not different treatmen.
procedures, but different groups of staff.

procedures, but different groups of staff.
Participating patients were then sent two postal questionnaires: a Disease Repercussions Profile (a measure of patient perceived handicap ${ }^{15}$ ) and a questionnaire about their expectations of treatment (these results are considered elsewhere). The ine question views and postal questionnaires in the six months preceding commencement of the trial. At their outpatient appointment, patients were interviewed by a member of the research team immediately before clinical assessment and the following patient questionnaires completed: demographic and resource use questionnaires demographic and resource use questionnaires
(interviewer completed); functional disability questionnaire (see below), pain (visual analogue) scales, ${ }^{16}$ self efficacy questionnaire, Hospital Anxiety and Depression Scale (psychological status) ${ }^{18}$ SF-36 (general health stathe measure) ${ }^{18}$ and Euro (gel EQ-5D (health (all self completed) n addition, a "process questionnaire" was placed in the patient's notes for completion by the doctor or physiotherapist seeing the patient, which asked for provisional diagnoses, tests ordered and the treatment or management options selected by the clinician.

At study follow up, patients were visited at home and completed all of the patient questionnaires again, with the exception of the expectations and demographic questionnaires. At baseline and at follow up, the order in which questionnaires were presented to patients was randomly assigned (to counteract possible order effects), the assignment lists having been previously prepared using random number tables. However, in all cases the demographic and resource use questionnaires, or resource use questionnaire alone (at study follow up) was administered before all others. General practitioners were sent a questionnaire asking them about their satisfaction with the orthopaedic service.

Various validated measures were used for measuring functional disability. For patients with sciatica, low back pain or neck pain, the Oswestry $^{21}$ back pain questionnaire was used for patients with upper limb disorders, the St Michael's Hospital Patient Self Evaluation-a version of the Modified American Shoulder and Elbow Surgeons Shoulder Patient Selfadministered; and for patients with lower limb disorders, the Western Ontario and McMaster Universities (WOMAC) Osteoarthritis Index ${ }^{23}$ was used. The EuroQol EQ-5D health status classification system was incorporated into the study because of its value in economic analyses. ${ }^{19} \mathrm{All}$ of the outcome instruments used in the study to attend ppointments for follow up interviews, questionnaires were sent to them by post.

SAMPLE SIZE AND SIGNIFICANCE TESTING

The power calculation indicated that a total of 600 patients would be required to detect a group difference in the means of 2 points on a ub-scale of the Disease Repercussions Profile $^{15}$ (possible score range 0 to 10 ) with $90 \%$ power at a $5 \%$ significance level. To allow for the multiple tests of significance performed on the secondary outcome measures (general health status (SF-36): 8 sub-scales, psychological status (HADS): 2 sub-scales, health state (Eurol EQ-5D): 2 measures, self effcacy: 2 (Euro (E) 
Table 1 Baseline characteristics: demographic characteristics and baseline scores for primary outcome measures

\begin{tabular}{|c|c|c|c|c|c|c|}
\hline & \multicolumn{3}{|c|}{$\operatorname{Doctor}(n=244)$} & \multicolumn{3}{|c|}{ Physiotherapist ( $n=237)$} \\
\hline $\begin{array}{l}\text { Demographic characteristics } \\
\text { Female } \\
\text { Age: mean (range) y } \\
\text { In paid employment } \\
\text { Married or cohabiting } \\
\text { Manual occupation }\end{array}$ & $\begin{array}{l}136 / 2 \\
48.6 / \\
119 / 2 \\
161 / 2 \\
90 / 21\end{array}$ & $\begin{array}{l}(55.7 \% \\
89) \\
(52.7 \% \\
(72.6 \% \\
42.3 \%)\end{array}$ & & $\begin{array}{l}113 / \\
48.37 \\
112 / \\
155 / \\
107 /\end{array}$ & $\begin{array}{l}(47.7 \\
7-87) \\
(52.3 \\
(72.4 \\
(52.7\end{array}$ & \\
\hline $\begin{array}{l}\text { Pain "in the last week": Visual Analogue Scales } \\
\text { Overall (0-100) } \\
\text { When resting (sitting or lying) }(0-100) \\
\text { When moving around }(0-100)\end{array}$ & $\begin{array}{l}\text { Mean } \\
52.8 \\
43.6 \\
50.3\end{array}$ & $\begin{array}{l}S D \\
25.3 \\
27.5 \\
27.5\end{array}$ & $\begin{array}{l}\text { Number } \\
211 \\
211 \\
211\end{array}$ & $\begin{array}{l}\text { Mean } \\
53.5 \\
47.4 \\
53.2\end{array}$ & $\begin{array}{l}S D \\
26.4 \\
29.5 \\
27.2\end{array}$ & $\begin{array}{l}\text { Number } \\
207 \\
207 \\
207\end{array}$ \\
\hline $\begin{array}{l}\text { Functional disability } \\
\text { Back / neck: Oswestry disability index (0-100) } \\
\text { Upper limb: St Michael's (worst extremity) (48-0) } \\
\text { Lower limb: total WOMAC score (0-96) }\end{array}$ & $\begin{array}{l}38.2 \\
30.7 \\
37.4\end{array}$ & $\begin{array}{l}15.5 \\
10.5 \\
22.4\end{array}$ & $\begin{array}{l}98(47 \%) \\
30(14 \%) \\
81(39 \%)\end{array}$ & $\begin{array}{l}38.8 \\
30.3 \\
34.9\end{array}$ & $\begin{array}{l}17.7 \\
10.4 \\
21.7\end{array}$ & $\begin{array}{l}102(50 \%) \\
34(17 \%) \\
66(33 \%)\end{array}$ \\
\hline $\begin{array}{l}\text { Perceived handicap (DRP) } \\
\text { Functional activities (0-10) } \\
\text { Social activities }(0-10) \\
\text { Socioeconomic status }(0-10) \\
\text { Relationships }(0-10) \\
\text { Emotions (0-10) } \\
\text { Body image }(0-10)\end{array}$ & $\begin{array}{l}7.5 \\
6.8 \\
3.7 \\
4.8 \\
6.9 \\
3.5\end{array}$ & $\begin{array}{l}3.4 \\
3.8 \\
4.5 \\
4.5 \\
3.9 \\
4.3\end{array}$ & $\begin{array}{l}214 \\
212 \\
199 \\
207 \\
206 \\
211\end{array}$ & $\begin{array}{l}7.8 \\
6.6 \\
4.6 \\
4.9 \\
6.7 \\
3.4\end{array}$ & $\begin{array}{l}3.0 \\
3.7 \\
4.5 \\
4.5 \\
3.8 \\
4.3\end{array}$ & $\begin{array}{l}205 \\
198 \\
193 \\
198 \\
198 \\
201\end{array}$ \\
\hline
\end{tabular}

correction to maintain the type 1 error level at $5 \%$ significance level ${ }^{24}$ would lead to use of significance threshold of 0.0025 .

ASSIGNMENT

Six orthopaedic consultants participated in the study. Stratified block randomisation was used, with stratification by consultant and using varying block sizes of between four and six, varying block sizes of between four and six,
depending on the number of available appointdepending on the number of available appoint-
ment slots in each consultant's clinic. Assignment was concealed by the use of opaque envelopes, which were opened sequentially (at the trial office) for each patient after informed consent had been obtained.

BLINDING

The study was not blinded and, in theory, patients knew who they had seen in clinic. However, all patient outcome measures (except economic data) were scored using self completed questionnaire data and are therefore unlikely to be susceptible to observer bias. Clinicans had to know that they were seeing a trial patient, because they had process questionnaires to complete, and this obviously has implications for bias. For example, clinicians might order more or fewer investigations for study patients.

ANALYSIS

The methods of scoring the various measurement instruments are described in appendix 1. Data were analysed using SPSS for Windows, release 6.1 , on an intention to treat basis. For all outcome measures, each patient's follow up score was subtracted from their baseline score to give a measure of difference between baseline and follow up. Where either baseline or follow up data were missing, that subject was excluded from the follow up analysis. The principal statistical analysis used was the use of independent $t$ tests to compare the means of the changes in outcome in each trial arm.

Cost effectiveness was studied from the viewpoints of both patients and the NHS. The measurement of cost effectiveness included mata collected both from each patient and from the member of staff who saw them in clinic.
Thus, costs were calculated separately for patient and staff derived data. Resource use was measured from time of randomisation to follow up. Information on numbers of visits for health care, and medications and devices used were collected retrospectively from patients at follow up. Information on tests ordered and management options selected by the surgeons or physiotherapists were completed during the consultations. Costs were calculated for the consultations. Costs were calculated for the
$1996 / 97$ financial year. Although median costs 1996/97 financial year. Although median costs are advantageous from a statistical point of mean that median values were often zero. Thus, we have calculated mean costs per patient. In addition, it has been argued that mean costs per patient are of more use to mean costs per patient are of more use to
health service planners (Joanna Coast, personal communication). A non-parametric test (the Mann-Whitney U test) was used to compare costs in each arm.

\section{Results}

During the enrolment period, 481 patients entered the trial. Baseline measures of primary outcome and demographic characteristics were broadly similar in the two arms (table 1) although the physiotherapist arm contained proportionately more men, and more manual workers than the junior doctor arm. Secondary outcome measures (not shown) were also simiin also simialso shows a similar distribution of anatomical sites of complaint across the two groups. Participant flow and follow up are illustrated in figure 1, which shows that the distribution of follow up times in the two arms was similar. Unfortunately, data on excluded patients were not collected. However, an audit of one consultant's referrals at Southmead for a four month period showed that 70 of $97(72.2 \%)$ patients were excluded as they were judged to require surgical intervention (the majority of these-31 cases-were for hip replacement operations)

Of the 191 patients assigned to a doctor who were included in the follow up analysis, there were six $(3.1 \%)$ protocol violations: four of these patients were seen by a physiotherapist, 


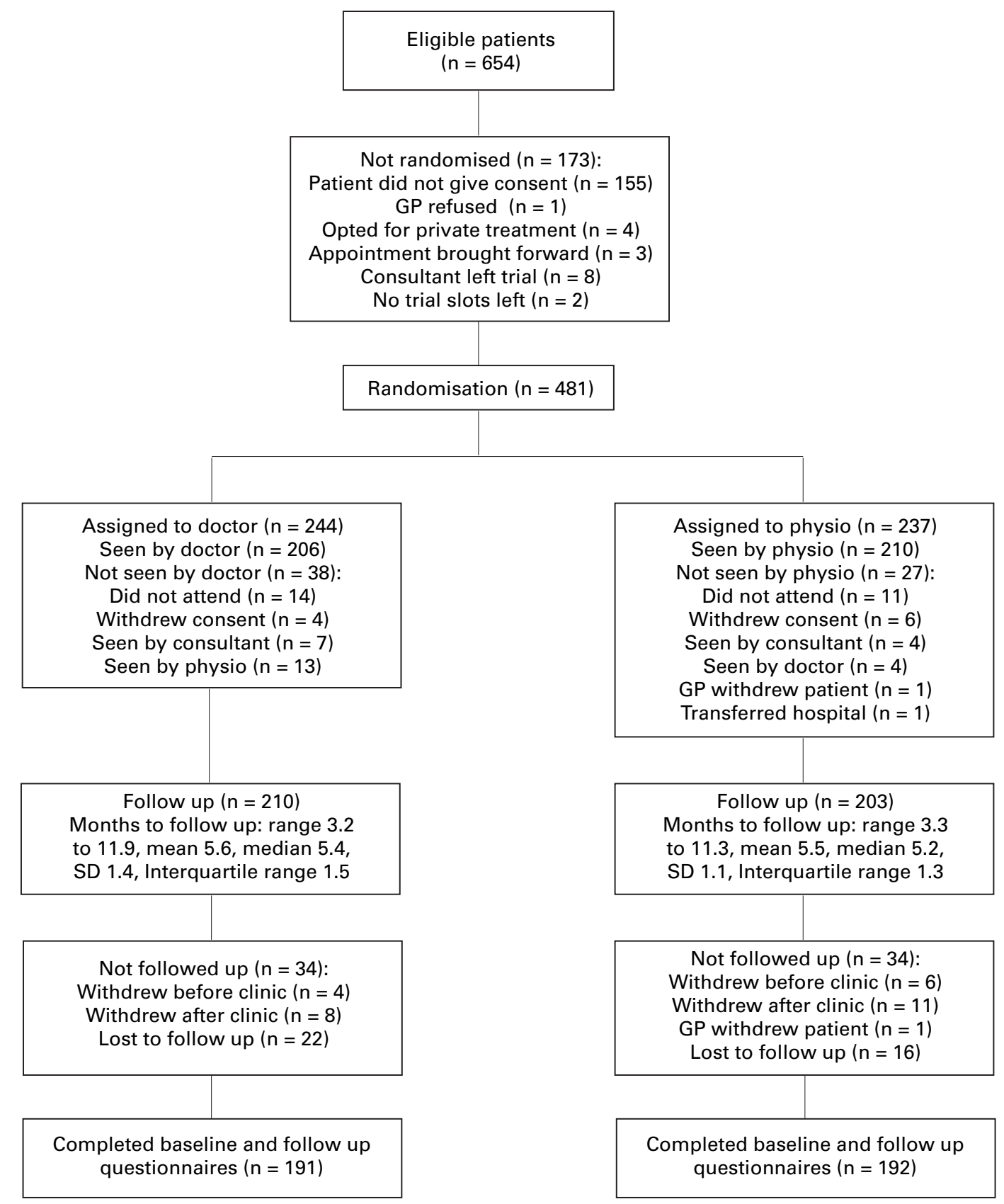

Figure 1 Participant flow and follow up.

and two were seen by consultant (rather than junior) orthopaedic surgeons. Of the 192 patients included in the follow up analysis from the physiotherapist arm, there were four protocol violations: one person was 17 years old and should have been excluded from the trial, and three patients were seen by a surgeon.

Tables 2 and 3 summarise the results of the trial. For the measures of pain, functional disability (that is, Oswestry, St Michael's or WOMAC, depending on anatomical site), perceived handicap (DRP), general health (SF-36), psychological status (HADS), health related quality of life (EuroQol EQ-5D) and self efficacy, table 2 shows the mean difference in scores between baseline and follow up. Patient and GP satisfaction (table 3) were only measured at follow up, and therefore only cross sectional comparisons can be made. For each outcome measure, $p$ values, point esti- mates and $95 \%$ confidence intervals for the differences in the means between groups are given.

Table 2 shows no clinically important differences between the two groups in primary outcome measures. After incorporation of the Bonferroni correction (tables 2 and 3) there were no statistically significant differences in secondary outcome measures except for the "perceived treatment quality" sub-scale of patient satisfaction (table 3), which slightly favoured the physiotherapist arm. With the possible exception of scores on the Disease
Repercussions Profile, changes in outcome measures were modest in size in both arms.

Table 4 shows the investigations ordered, and the management options selected. Physiotherapists were significantly more likely to order no investigations at a orders liograph. Other in 
Table 2 Improvement scores (baseline minus follow up) for primary and secondary outcome measures (for each measure the first stated number indicates the better state,

\begin{tabular}{|c|c|c|c|c|c|c|c|c|}
\hline \multirow[b]{2}{*}{ Outcome measure } & \multicolumn{3}{|l|}{ Doctor } & \multicolumn{3}{|c|}{ Physiotherapist } & \multirow[b]{2}{*}{$p$ difference } & \multirow{2}{*}{$\begin{array}{l}\text { Point estimate } \\
(95 \% \text { CI) for } \\
\text { difference }\end{array}$} \\
\hline & Number & Mean change & $S E M$ & Number & Mean change & $S E M$ & & \\
\hline \multicolumn{9}{|l|}{ Pain (Visual Analogue Scale) } \\
\hline Overall $(0-100)$ & 189 & 7.0 & 1.9 & 188 & 10.3 & 2.2 & 0.3 & $-3.3(-8.9,2.5)$ \\
\hline When resting $(0-100)$ & 190 & 5.6 & 2.1 & 189 & 10.0 & 2.2 & 0.1 & $-4.4(-10.3,1.5)$ \\
\hline When moving around $(0-100)$ & 189 & 4.9 & 1.9 & 188 & 9.2 & 2.3 & 0.2 & $-4.3(-10.4,1.6)$ \\
\hline Oswestry Disability Index $(0-100)$ & 84 & 5.4 & 1.4 & 91 & 2.7 & 1.7 & 0.2 & $2.7(-1.7,7.2)$ \\
\hline St Michael's (48-0) & 27 & -1.0 & 2.0 & 31 & -1.3 & 1.6 & 0.9 & $-2.3(-4.9,5.5)$ \\
\hline WOMAC Score $(0-96)$ & 75 & 6.3 & 2.0 & 60 & 10.6 & 2.2 & 0.2 & $-4.3(-10.2,1.7)$ \\
\hline \multicolumn{9}{|l|}{ Perceived handicap (DRP) } \\
\hline Functional activities $(0-10)$ & 191 & 2.5 & 0.3 & 179 & 2.7 & 0.3 & 0.6 & $-0.2(-1.1,0.6)$ \\
\hline Social activities $(0-10)$ & 187 & 2.6 & 0.3 & 171 & 2.7 & 0.3 & 0.8 & $-0.1(-1.0,0.8)$ \\
\hline Socioeconomic status $(0-10)$ & 176 & 1.4 & 0.3 & 167 & 1.9 & & 0.3 & $-0.5(-1.4,0.4)$ \\
\hline Relationships $(0-10)$ & 183 & 2.6 & 0.3 & 175 & 1.6 & 0.5 & 0.1 & $1.0(-0.3,2.2)$ \\
\hline Emotions $(0-10)$ & & 2.6 & 0.3 & 174 & 3.0 & 0.3 & 0.4 & $-0.4(-1.3,0.6)$ \\
\hline Body image $(0-10)$ & 186 & 1.8 & 0.3 & 174 & 0.8 & 0.6 & 0.1 & $1.0(-0.2,2.3)$ \\
\hline \multicolumn{9}{|l|}{ General Health (SF-36) } \\
\hline Physical functioning (100-0) & 190 & -6.0 & 1.4 & 189 & -6.0 & 1.5 & 0.8 & $0.0(-4.5,3.7)$ \\
\hline Role physical $(100-0)$ & 188 & -6.5 & 3.2 & 188 & -7.9 & 2.8 & 0.8 & $1.4(-7.1,9.7)$ \\
\hline Bodily pain $(100-0)$ & 193 & -7.2 & 1.6 & 189 & -9.0 & 1.7 & 0.4 & $1.8(-2.8,6.5)$ \\
\hline General health $(100-0)$ & 189 & -0.3 & 1.2 & 183 & -3.3 & 1.3 & 0.1 & $3.0(-0.4,6.6)$ \\
\hline Vitality $(100-0)$ & 192 & -4.2 & 1.4 & 187 & -2.7 & 1.5 & 0.5 & $-1.5(-5.5,2.6)$ \\
\hline Social functioning $(100-0)$ & 193 & -7.5 & 2.2 & 189 & -7.4 & 2.2 & 1.0 & $-0.1(-6.1,6.0)$ \\
\hline Role emotional $(100-0)$ & 186 & -4.3 & 3.6 & 186 & -6.6 & 3.5 & 0.6 & $2.3(-7.5,12.2)$ \\
\hline Mental health $(100-0)$ & 192 & -3.1 & 1.3 & 187 & -2.5 & 1.3 & 0.8 & $-0.6(-4.1,3.0)$ \\
\hline \multicolumn{9}{|l|}{ Psychological status (HADS) } \\
\hline Anxiety $(0-21)$ & 192 & 0.6 & 0.2 & 184 & 1.0 & 0.3 & 0.4 & $-0.4(-1.0,0.4)$ \\
\hline \multirow{2}{*}{\multicolumn{9}{|c|}{ EuroQol $E Q-5 D$}} \\
\hline & & & & & & & & \\
\hline $\begin{array}{l}\text { Health state score }(1.00 \text { to }-0.59) \\
\text { "Thermometer" score }(100-0)\end{array}$ & $\begin{array}{l}192 \\
190\end{array}$ & $\begin{array}{l}-0.1 \\
-1.7\end{array}$ & $\begin{array}{l}0.0 \\
1.6\end{array}$ & $\begin{array}{l}190 \\
190\end{array}$ & $\begin{array}{l}-0.1 \\
-4.0\end{array}$ & $\begin{array}{l}0.0 \\
1.6\end{array}$ & $\begin{array}{l}0.9 \\
0.3\end{array}$ & $\begin{array}{l}0.0(-0.1,0.1) \\
2.3(-2.2,6.7)\end{array}$ \\
\hline \multicolumn{9}{|l|}{ Self efficacy } \\
\hline Pain (50-5) & 189 & $\begin{array}{l}-3.5 \\
-37\end{array}$ & 0.9 & 190 & -3.7 & 0.9 & 0.8 & $\begin{array}{l}0.2(-2.3,2.7) \\
-0 .(-21,4)\end{array}$ \\
\hline Other symptoms $(40-4)$ & 191 & -3.7 & 0.6 & 187 & -3.3 & 0.7 & 0.7 & $-0.4(-2.1,1.4)$ \\
\hline
\end{tabular}

between the study arms. Physiotherapists were much more likely than doctors to record that they had given advice and reassurance to the patient. Doctors were more likely to give intramuscular injections and refer patients for orthopaedic surgery. Clinicians were also asked whether they were able to reach a diagnosis and whether or not they had consulted with the consultant or senior orthopaedic surgeon on duty at the time. The differences between the two arms were not statistically significant: 183 of $206(88.8 \%)$ doctors and 196 of $220(89.1 \%)$ physiotherapists were able to give a provisional diagnosis, and 48 of $169(28.4 \%)$ doctors and 52 of $206(25.2 \%)$ physiotherapists said that they had consulted with a senior orthopaedic surgeon.

In the absence of statistically or clinically significant differences between groups in either primary outcome measures or the EuroQol EQ-5D scores, the economic analysis proceeded as a cost minimisation analysis. ${ }^{19}$ Table 5 illustrates patient derived data on resources greater satisfaction)

\begin{tabular}{|c|c|c|c|c|c|c|c|c|}
\hline \multirow[b]{2}{*}{ Outcome measure } & \multicolumn{3}{|l|}{ Doctor } & \multicolumn{3}{|c|}{ Physiotherapist } & \multirow[b]{2}{*}{$p$ difference } & \multirow{2}{*}{$\begin{array}{l}\text { Point estimate } \\
\text { (95\%) CI for } \\
\text { difference }\end{array}$} \\
\hline & Number & Mean & SEM & Number & Mean & SEM & & \\
\hline \multicolumn{9}{|l|}{ Patient dissatisfaction } \\
\hline Overall $(1-7)$ & 200 & 2.9 & 0.1 & 198 & 2.7 & 0.1 & & $0.2(-0.1,0.5$ \\
\hline Staff communication / attitudes (19-95) & 202 & 47.8 & 0.9 & 200 & 43.2 & 0.8 & 0.006 & $4.6(2.2,6.8)$ \\
\hline Perceived treatment quality (13-65) & 202 & 31.0 & 0.7 & 200 & 28.0 & 0.6 & 0.001 & $3.0(1.3,4.9)$ \\
\hline Facilities (5-25) & 202 & 12.1 & 0.3 & 200 & 11.2 & 0.2 & 0.006 & $0.9(0.3,1.7)$ \\
\hline \multicolumn{9}{|l|}{ GP dissatis } \\
\hline $\begin{array}{l}\text { Own dissatisfaction (1-7) } \\
\text { Perceived patient's dissatisfaction (1-7) }\end{array}$ & $\begin{array}{l}176 \\
205\end{array}$ & $\begin{array}{l}2.3 \\
4.9\end{array}$ & 0.8 & 195 & $\begin{array}{l}2.6 \\
4.8\end{array}$ & $\begin{array}{l}0.8 \\
0.2\end{array}$ & $\begin{array}{l}0.4 \\
0.7\end{array}$ & $\begin{array}{l}0.1(-0.3,0.1 \\
0.1(-0.5,0.7\end{array}$ \\
\hline & & & & & & & & $0.1(-0.3,0.1$ \\
\hline
\end{tabular}

sed between randomisation and follow up, and these results, along with the process data in table 4 have been used to generate the cost data in table 6. Baseline economic data were used to assess whether any devices were bought before domisation or not

There were no statistically significant differTirect costs to patients in each arm, and there were no significan erences in primary care costs. There were ifferences in hospital costs when calculated from data supplied by the doctors a when compared with the physiotherapist irm, and they relate to the higher number and the larger numbers referred for orthopaedic surgery. It should be noted that the significant differences in salary costs would be largely removed if it were shown that the doctors had spent less time with their patients (see discussion). 
Table 4 Investigations and management options selected by the doctor or physiotherapist

\begin{tabular}{llll}
\hline Investigations & Doctor & Physiotherapist & Significance* \\
\hline None & $32 / 217$ & $106 / 223$ & $<0.000001$ \\
Plain radiographs & $90 / 217$ & $31 / 223$ & $<0.000001$ \\
Bone scan & $2 / 217$ & $1 / 223$ & 0.55 \\
MRI & $74 / 217$ & $61 / 223$ & 0.15 \\
Computed tomography & $10 / 217$ & $11 / 223$ & 1.00 \\
Nerve conduction studies & $2 / 217$ & $4 / 223$ & 0.43 \\
Full blood count & $4 / 217$ & $4 / 223$ & 1.00 \\
Erythrocyte sedimentation rate & $3 / 217$ & $4 / 223$ & 1.00 \\
C reactive protein & $1 / 217$ & $4 / 223$ & 0.38 \\
Uric acid & $0 / 217$ & $0 / 223$ & - \\
RA latex & $3 / 217$ & $2 / 223$ & 0.98 \\
Other investigations & $5 / 217$ & $1 / 223$ & 0.12 \\
Management options & & & \\
Advice $/$ reassurance & $63 / 194$ & $116 / 197$ & $<0.000001$ \\
Referral to other hospital specialist & $5 / 195$ & $2 / 197$ & 0.28 \\
Discharged to GP with information & $20 / 195$ & $18 / 197$ & 0.84 \\
Discharged to GP with plan & $3 / 195$ & $4 / 197$ & 1.00 \\
Intra-articular injection & $19 / 195$ & $16 / 197$ & 0.70 \\
Intra-muscular injection & $7 / 195$ & $1 / 197$ & 0.04 \\
Prescription for NSAID / analgesics & $4 / 195$ & $0 / 197$ & 0.06 \\
One off physiotherapy intervention $\neq$ & $0 / 195$ & $6 / 197$ & - \\
Referral for physiotherapy & $46 / 195$ & $42 / 197$ & 0.68 \\
Referral for orthotics / appliances & $15 / 195$ & $25 / 197$ & 0.14 \\
Referral to the pain clinic & $15 / 195$ & $8 / 197$ & 0.19 \\
Referral for orthopaedic surgery & $33 / 195$ & $14 / 197$ & 0.005 \\
\hline
\end{tabular}

*Significance values are for $\chi^{2}$ test with continuity correction, or Fisher's exact two tailed test where any cell value $<5$. †At Frenchay, MRI was pre-booked by the consultant orthopaedic surgeon after reading the referral letter. $¥$ This management option was only available to orthopaedic physiotherapy specialists. \At Southmead, referrals where surgery was indicated from the referr letter were excluded from the trial. At Frenchay, trial patients included surgical referrals.

Table 5 Patient derived data on resources used between randomisation and follow up

\begin{tabular}{lllll}
\hline Resource & Doctor & Number & Physiotherapist & Number \\
\hline Mean number of hospital visits & 2.3 & 209 & 2.9 & 202 \\
Proportion visiting general practitioners & $51.9 \%$ & 208 & $48.3 \%$ & 203 \\
Mean visits to general practice & 1.0 & 208 & 1.2 & 203 \\
Proportion reporting GP home visits & $1.0 \%$ & 208 & $3.5 \%$ & 203 \\
Mean number of GP home visists & 0.02 & 208 & 0.08 & 203 \\
Proportion receiving prescriptions & $48.6 \%$ & 208 & $54.0 \%$ & 202 \\
Mean number of prescriptions & 1.5 & 209 & 1.5 & 202 \\
Mean visits to privatelalternative practice & 2.59 & 208 & 3.44 & 201 \\
Proportion using over the counter medicines & $42.1 \%$ & 209 & $37.9 \%$ & 202 \\
Proportion using alternative remedies & $28.2 \%$ & 209 & $23.2 \%$ & 203 \\
Proportion buying devices themselves & $1.5 \%$ & 198 & $3.6 \%$ & 196 \\
Proportion receiving devices on NHS & $7.7 \%$ & 196 & $10.1 \%$ & 198 \\
Proportion having home help/meals on wheels & $5.3 \%$ & 209 & $4.0 \%$ & 201 \\
\hline
\end{tabular}

Discussion

The aims of this study were to compare the effectiveness and the cost effectiveness of physiotherapists working in an extended role in outpatient orthopaedic departments. The results suggest that physiotherapists are as effective as post-Fellowship junior staff and clinical assistant orthopaedic surgeons in the assessment and initial management of new referrals, that the use of these physiotherapists leads to lower initial direct hospital costs, and that patients are more satisfied with care provided by these members of staff than they are with surgeons in training providing the same service. Future studies should examine long term outcomes and resource use.

Overall, our analyses of primary outcomes at follow up suggests that there were no clinically significant changes in either trial arm, with the exception of borderline changes in perceived handicap. A change of $15-20 \mathrm{~mm}$ on a $100 \mathrm{~mm}$ visual analogue pain scale is considered clinically significant in clinical trials in rheumatology (Paul Dieppe, personal communication) and mean reductions of this magnitude were not achieved in either arm by the time of follow up. When patients were followed up, some were still awaiting the results of investigations, some
KEY POINTS

- The triage of new referrals to outpatient orthopaedic departments can be done as well by suitably trained physiotherapists as by sub-consultant surgeons.

- Patients who were seen by an extended role physiotherapist reported greater levels of satisfaction at follow up than those who were seen by a surgeon.

- The use of these physiotherapists leads to lower initial direct hospital costs for the NHS.

were undergoing or awaiting treatment, and others had been discharged having been told that there was no intervention for them. These factors are reflected in the much lower costs for treatments that patients reported that they had actually received by follow up, compared with the costs of the tests and treatment that physiotherapists or surgeons in training had ordered for them. Clearly, the study would have benefited from a longer follow up. However, resources did not allow this.

The fact that more doctors ordered radiographs or referred more patients for orthopaedic surgery may reflect their training. What is remarkable is that for all other investigations remarkable is that for all other investigations the two groups were not significant. More physiotherapists reported that they gave advice or reassurance to patients, and these differences may go some way to explaining the differences in patient satisfaction scores. Both f the differences would suggest that both physiotherapists spent more time with their patients. Unfortunately, data on consultation times were not collected. Although the physiotherapists at Southmead had 30 minute appointment slots (compared with 20 minutes for surgeons), at Frenchay the appointment slots were the same for either specialist. However, a sub-group analysis of patient satisfaction scores at each study site (results not shown) showed that increased satisfaction with physiotherapists remained at Frenchay alone. These results may be explained by differences in age or years of clinical experience between taff in the two arms. However, as we did not in the two arm comment.

The main conclusion that we draw from the findings of this randomised study is that the triage of new referrals to outpatient orthopaedic departments can be done as well by suitably trained physiotherapists as by sub-consultant orthopaedic surgeons. This finding supports those of earlier, uncontrolled studies. ${ }^{9-12}$ The main limitations of our study were the short follow up time, a lack of blinding and the different selection criteria used at the two hospital sites. However, the latter "pragmatic" feature of our study is in some respects a benefit as it reflects the "real world" in that these extended role physiotherapists are used in difextent ways in different units. Indee ss of these posts is dependent upon the individual physiotherapist 
Table 6 Mean direct costs to the patient, and to the NHS (derived from the activity data in tables 4 and 5)

\begin{tabular}{|c|c|c|c|}
\hline Mean resource costs per patient & Doctor & Physiotherapist & $\begin{array}{l}\text { p for difference } \\
\text { (Mann-Whitney U test) }\end{array}$ \\
\hline \multicolumn{4}{|l|}{ Direct costs to the patient ${ }^{*}$} \\
\hline & $\begin{array}{l}\text { (n).01 } \\
(\mathrm{n}=198)\end{array}$ & $\begin{array}{l}\ldots 0.00 \\
(\mathrm{n}=189)\end{array}$ & \\
\hline (b) Travel costs to GP surgery† & $\begin{array}{l}f_{(\mathrm{n}} 0.50 \\
(\mathrm{n}=172)\end{array}$ & $\begin{array}{l}f 0.45 \\
(n=175)\end{array}$ & 0.7 \\
\hline (c) Prescription costs $\ddagger$ & $\begin{array}{l}£_{1} 2.89 \\
(\mathrm{n}=207)\end{array}$ & 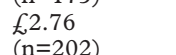 & 0.9 \\
\hline (d) Over the counter medicines & $\begin{array}{l}f 3.93 \\
(n=202)\end{array}$ & $\begin{array}{l}f 3.94 \\
(n=202)\end{array}$ & 0.6 \\
\hline (e) Alternative remedies & $\begin{array}{l}£_{3}^{3.17} \\
(\mathrm{n}=205)\end{array}$ & $\begin{array}{l}\underset{f}{2} .18 \\
(\mathrm{n}=201)\end{array}$ & 0.3 \\
\hline (f) Gadgets & $\begin{array}{l}f_{1}^{1.73} \\
(\mathrm{n}=198)\end{array}$ & $\begin{array}{l}\ldots 5.55 \\
(\mathrm{n}=196)\end{array}$ & 0.4 \\
\hline (g) Private help and meals on wheels & $\begin{array}{l}f 11.29 \\
((1)=208)\end{array}$ & $£ 9.85$ & 0.7 \\
\hline (h) Private and alternative practitioners $\rrbracket$ & $\begin{array}{l}£ 20.13 \\
(\mathrm{n}=205)\end{array}$ & $\underset{(n=199)}{£_{(19}}$ & 0.7 \\
\hline Total (a) to (h) & $\begin{array}{l}f 50.10 \\
(\mathrm{n}=204)\end{array}$ & $\begin{array}{l}£ 88.75 \\
(\mathrm{n}=198)\end{array}$ & 0.8 \\
\hline \multicolumn{4}{|l|}{ NHS costs: (i) Hospital costs** } \\
\hline (a) Salary costs of specialist seen ${ }^{\star}+\dagger$ & $\begin{array}{l}£ 7.28 \\
(\mathrm{n}=209)\end{array}$ & $\begin{array}{l}f_{(n=202)} \\
(n=202)\end{array}$ & $<0.00001$ \\
\hline (b) Investigations ordered $\ddagger \ddagger$ & $\begin{array}{l}£ 20.81 \\
(\mathrm{n}=217)\end{array}$ & $\begin{array}{l}£_{1} 14.02 \\
(\mathrm{n}=221)\end{array}$ & $<0.00001$ \\
\hline (c) Management options selected $¥ \neq \mathbb{S}$ & $\begin{array}{l}£ 471.32 \\
(\mathrm{n}=195)\end{array}$ & $\begin{array}{l}£ 236.57 \\
(\mathrm{n}=196)\end{array}$ & $<0.001$ \\
\hline $\operatorname{Total}(\mathrm{a})+(\mathrm{b})+(\mathrm{c}) \boldsymbol{\pi}$ & $\begin{array}{l}£ 498.38 \\
(n=238)\end{array}$ & $\begin{array}{l}£ 255.55 \\
(\mathrm{n}=232)\end{array}$ & $<0.00001$ \\
\hline (d) Treatment received by follow up ${ }^{\star a a}$ & $\begin{array}{l}£ 192.09 \\
(n=204)\end{array}$ & $\begin{array}{l}f_{1} 154.55 \\
(\mathrm{n}=198)\end{array}$ & 0.6 \\
\hline (e) Devices supplied by hospital ${ }^{\star}$ & $\begin{array}{l}£_{(7.14} \\
(=196)\end{array}$ & $£$ & 0.4 \\
\hline Total (d) $+(\mathrm{e}) \boldsymbol{\pi}$ & $\begin{array}{l}f_{1} 189.87 \\
(\mathrm{n}=210)\end{array}$ & $\begin{array}{l}£ 164.50 \\
(\mathrm{n}=201)\end{array}$ & 0.2 \\
\hline \multicolumn{4}{|l|}{ NHS costs: (ii) Primary care costs ${ }^{\star}$} \\
\hline (a) GP consultations - at practice $\int \uparrow$ & $\begin{array}{l}\underset{1}{f} 16.54 \\
(\mathrm{n}=208)\end{array}$ & $\begin{array}{l}f_{(n=203)} \\
(\mathrm{n}=20.76\end{array}$ & 0.8 \\
\hline (b) GP consultations - home visits ${ }^{\mathrm{sa}}$ & $\begin{array}{l}f 0.90 \\
(\mathrm{n}=208)\end{array}$ & $\begin{array}{l}f 3.94 \\
(\mathrm{n}=203)\end{array}$ & 0.08 \\
\hline (c) Prescription costs to NHS $S^{\star \star \star \star}$ & $\begin{array}{l}f 18.04 \\
(\mathrm{n}=208)\end{array}$ & $\begin{array}{l}f 20.36 \\
(\mathrm{n}=202)\end{array}$ & 0.5 \\
\hline Total $(a)+(b)+(c) \uparrow$ & $\begin{array}{l}\ldots 35.74 \\
(\mathrm{n}=202)\end{array}$ & $\begin{array}{l}f_{(42.11} \\
(\mathrm{n}=192)\end{array}$ & 0.17 \\
\hline
\end{tabular}

${ }^{*}$ Patient derived data (see table 5). $†$ Calculated as number of appointments between baseline and follow up multiplied by cost of journey (car and bicycle costs calculated as $£ 0.25$ per mile). ¥Where patients paid for prescriptions, charges at 1 April 1996 were used. SIncludes costs of private health care (including investigations, physiotherapy and inpatient treatment), chiropractice,
homeopathy, physiotherapy, osteopapathy, acupuncture, aromatherapy, chiropractice, reflexology, shiatsu and acupressure (when paid for by the patient). ${ }^{a}$ This high mean cost is largely attributable to one patient in the physiotherapist arm who elected for private treatment for the removal of a prolapsed disc (total cost $£ 6660$, including private outpatient appointments and investigations). In the junior doctor arm, the highest cost incurred was $£ 1691$ in the case of a patient who elected for private treatment of a meniscal tear. In calculating mean total costs for each patient, where indifor a person who completed other items, missing values were substituted with the mean value for that cost in the relevant trial arm. ${ }^{\star}$ Costs are $1996 / 97$ General Practice Fund Holder prices supplied by the Finance Department at Southmead Hospital. Salary costs are September 1996 rates of pay. + Hased on number of outpatient appointments at orthopaedic department. Cost per appointment slot $=£ 6.33$ for physiotherapists and $£ 6.85$ for junior doctors, based on: midpoint of salary scales for full time staff, including superannuation and on costs, assuming staff work 47
5 day weeks a year and see 8 patients per half day clinic session. NB: These costs assume that doc5 day weeks a year and see 8 patients per half day clinic session. NB: These costs assume that docattending clinician (see table 4). S\$For the option "orthopaedic surgery" a cost of $£ 2229.25$ was used, based on the average cost of the following operations: laproscopy day case, laproscopy inpatient, arthroscopy day case, arthroscopy inpatient, total knee replacement and hip replacement. Includes outpatient appointments (including appointments for physiotherapy and follow ups), surgery (inpatient and day case), scans and other investigations, chiropody, health visiting, and ten and Dennett $(1996))^{25} \star \star \star \star \star$ Calculated as drugs costs as per British National Formulary number 32 (September 1996), plus an overhead charge per prescription $(€ 9.30$, the estimated cost to the NHS of prescribing and dispensing a single item), less any charge paid by the patient. Where patient derived data on prescriptions were missing, the data were taken from general practice case notes in $54 / 76(71.1 \%)$ cases.

adapting to the individual working methods of the consultant orthopaedic surgeon involved. ${ }^{9}$

Waiting lists for orthopaedic surgery have traditionally been long, and it has been suggested that the majority of general practitioner referrals are for conditions where surgery would not be an effective intervention. ${ }^{11}$ Of course, our study says noth- ing about the quality of the care provided by each group of clinicians. However, given that the numbers of physiotherapists being trained for these posts seems to be increasing nationally, it would appear as though there will be many opportunities for future comparative studies, which might usefully focus on longe outcomes than we did, including costs, and perhaps incorporate objective measures of outcome. These future studies might also examine the possible benefits to orthopaedic surgeons of these new initiatives, such as increased time for their own specialist training, or more time for consulting with their surgical patients. The role of specially trained physiotherapists, as of all health professionals, is constantly changing. Where possible, different ways of working should be evaluated so as to identify their effects on patient outcomes.

An edited version of this paper was presented at The Society for diff, 16-18 September 1998. Andrea Wilson, worked as the full time research secretary to this study. Joanna Coast and Suzanne
Richards provided health economics advice. Sara Brookes, proFinance Department, and Janice Osborne, Orthopaedic Department, Southmead Hospital. The following consultant e trial: Gordon Bannister, Ian Nelson, Ruth Case (locum), Evert Smith, Christopher Ackroyd and Neil Blewitt. Appointments for trial patients were booked by Mary Harr (Sank Vivienne Tomkinson, Nasor Ali and all the staff of the Centre, Southmead Hospital and the Department of Orthopaedic Surgery, Frenchay Hospital, for patients, general practitioners, orthopaedic physiotherapy speialists and orthopaedic surgeons who provided us with the dat or this trial. The $2 \mathrm{~F}-36$ health survey-United Kingdom-Englis Depression Scale is copyright R P Snaith and A S Zigmond 1983, 1992, 1994, and was used with permission of NFER-
NELSON, Berks, UK. The Boston Patient Expectations and atisfaction Questionnaire as used in this study, was developed nder NIH grant \#AR36308. Information on scoring the St Michael's Hospital Patient Self Evaluation was provided by Dorcas Beaton, Research Clinician, St Michasers Hospita nonymous referees who commented on earlier drafts of this paper.

Funding: the study described in this paper was funded by the Directorate, under the Primary/Secondary Care Interface Orthopaedic Physiotherapy Specialist posts at Southmead were fonflicts of interest: none.

\section{Appendix 1}

AIN SCALES: Visual analogue scales of $100 \mathrm{~mm}$ length were use ${ }^{16}$ to record patients experience of pain in the week preceding interview. Three measurements were taken: overall pain, pain at rest and pain while moving (higher score equals greater wain).

OSWESTRY BACK PAIN QUESTIONNAIRE: Responses on the 10 six point scales were converted to an Oswestry Disability Index that expressed scores as a percentage of the maximum possible score (that is, adjusting for missin values for each patient). ${ }^{21}$ Thus, the range of possible individual scores was $0-100$ (higher score equals greate functional disability).

T MICHAEL'S HOSPITAL PATIENT SELF EVALUATION: Responses on the 16 four point scales were summed for the injured side (where both sides were injured, the lowest score was used). Missing values were replaced by the average of the other item scores when fewer than 10 per cent of the items were missing (D Beaton, personal communication). The range of possible individua scores was $0-48$ (lower score equals greater functional disability). 
WOMAC OSTEOARTHRITIS INDEX: This instrument consists of three sub-scales (pain: 5 items, stiffness: 2 item physical function: 17 items), although for ease comparison with the other functional disability measures used in this study, the three items were summed to give a total WOMAC score. Where one pain item, on stiffness item or less than four physical function items were missing from a patient's responses, an average value of their other responses on that sub-scale was subvitued for the missing valu of The range of possible individual scores was $0-9$ functional disability)

PROFI $\mathrm{E}^{15}$ : Where respondents ndicated that their musculoskeletal condition did affect dimension of their lives (functional activities, social activities, socioeconomic status, relationships, emotions or body image) they were asked to rate the importan of this effect on an 11 point scale. Where there was no of this effect on an 11 point scale. Where there was no effect, a score of zero was substituted. Missing values scores was $0-10$ (higher score equals greater perceived handicap)

SF-36: The eight sub-scales of this questionnaire were scored as described in the scoring manual. ${ }^{26}$ The sub-scales are all scored positively so that a higher score indicates better functioning, better health, or less pain. HOSPITAL ANXIETY AND DEPRESSION SCALE (HADS): This instrument consists of two seven item sub-scales (anxirange of an individual's possible scores for each sub-scale is $0-21$ (higher score equals greater anxiety or depression

EUROQOL EQ-5D: Although we were simultaneously administering the SF-36 general health survey, the EuroQol EQ-5D was included in the study because of its value in economic analyses of health care. The EuroQol EQ-5D generates two scores. Firstly, a health state, of which there are a possible 243 states, based on data collected from a representative sample of the UK population. The range of healh state scores is -0.59 (worst heal "thate) to 1.00" (best health state). Secondly,

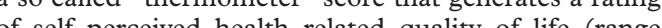
cqu $0-100$, the higher the score the better the self perceived quality of life). perceived quality of life)

pain (five items) and othement contains two sub-scales: items are 10 point $(1-10)$. Sub-scale scores were derived by summing all items in each scale. Where fewer than 50 per cent of the items in a scale were missing, we substtuted the mean score for the items comprising that scale which were completed. The range of an individual's possible scores was 5-50 for pain (higher value equals less pain) and 4-40 for other symptoms (higher value equals less effect on other symptoms)

PATIENT SATISFACTION: A 37 item instrument, based on he Boston Patient Expectations and Satisfaction Questionnaire and the Leeds Patient Sadifaction $\mathrm{Scale}^{28}$ was used. The results were analysed for four sub-scales: staff communication and perceived attitudes to patient (19 items, possible score range 19 to 95), treatment quality (13 items, possible score range 13 to 65), clinic facilities (5 items, possible score range 5 to 25 ) and overall satisfaction (1 item, range 1 to 7 ). Given the topic of inquiry, a deliberate emphasis was placed on satisfaction with staf. All items were scored using 5 point Likert scales, except the overall satisfaction compon's which was 7 point. Where less th applicable to that patient) they were subsituted by the mean value of the other scores on that scale. Lower scores represent greater satisfaction.

GP SATISFACTION: Two 7 point Likert scales were used to measure GP satisfaction and the GP's perception of the atient's satisfaction (higher scores represent greate satisfaction)

1 Hopkins A, Solomon J, Abelson J. Shifting boundaries in

2 English T Personal paper: Medicine in the 1990s needs team approach. $B M \mp 1997 ; 314: 661-3$.

3 Heath I. Skill mix in primary care. BMf 1994;308:993-9. 4 Sag-5. 5 Dowling S, Barrett S, West R. With nurse practitioners, who needs house officers? $B M Y$ 1995;311:309-13.

junior doctors' work: a confusion of accountability. $B M \mathcal{A}$ 1996;312:1211-14.

Haslam D. Skill-mix in primary care: sharing clinical work1996;46:639-40. 8 Casey N, Smith

R. Bringing nurses and doctors closer Weatherley CR. Initial assessment and referred to a spinal clinic. $f R$ Soc Med 1994;87:213-14. 10 Hockin J, Bannister G. The extended role of a physiothera-
pist in an out-patient orthopaedic clinic. Physiotherapy 1994;80:281-4. Weale AE, Bannister G. Who should see orthopaedic
outpatients - physiotherapists or surgeons? Ann $R$ Coll Sur Engl 1995;77 (suppl):71-3.
Engl

By approach. Physiotherapy 1989;75:435-7.
Durrell S. Expanding the scope of physiotherapy: clinical Theratherapy specialists in con of

4 Roland $M$, Torgerson D

. Understanding controlled trials: arr AJ. Margaret Holroyd prize essay: A patient-centred approach to evaluation and treatment in rheumatoid arthritis: the development of a clinical tool to measure
patient-perceived handicap. Br $\mathcal{F}$ Rheumatol 1996;35:921

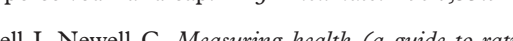
scales and questionaires). 2nd ed. Oxford: Oxford University

7 Barlow JH, Williams B, Wright CC. The reliability and . Psychology, Health and Medicine 1997; 2:
Bowling A. Measuring disease: a review of dise-specific qual ity of life $n$ mas
Press, 199 .

19 Drummond MF, O'Brien B, Stoddart GL, et al. Methods for the economic evaluation of health care programmes. 2nd ed.

Anon. EuroQol EQ-5D user guide. Mimeo, 1996. Available from Paul Kind, Centre for Health Economics, University

of York, York Y01 5DD.
Fairbank JCT, Cooper J, Davies JB, et al. The Oswestry low
back pain disability questionnaire. Physiotherapy 1980;66: $271-3$.
Beaton DE, Richards RR. Measuring function of the shoulBeaton DE, Richards RR. Measuring function of the shoul-
der. A cross-sectional comparison of five questionnaires. Bone foint Surg Am 1996;78:882-90

3 Bellamy N. WOMAC Osteoarthritis Index: A userr's guide. London, Ontario: mimeo, 1995. Available from Nichola tal, 375 ' South Street, London (ON) N6A 4G5, Canada. Altman DG. Practical statistics for medical research. London:

5 Netten A, Dennett J. Unit costs of health and social care.

University of Kent, 1996. S
Medical Outcomes Trust. SF-36 Health Survey. Scoring manual for English-language adaptations: AustralialNeww Zea7 Karlson EW, Daltroy LH, Liang MH, et al. Gender differences in patient preferences may underlie differentis

28 Hill J, Bird HA, Hopkins R, et al. Survey of satisfaction with care in a rheumatology out-patient clinic. Ann Rheum $D$ 